\title{
O DISCURSO COMO OBJETO-DE-DISCURSO EM EXPRESSÕES NOMINAIS ANAFÓRICAS
}

\author{
CLÉLIA CÂNDIDA ABREU SPINARDI JUBRAN \\ (UNESP-Assis/CNPq)
}

\begin{abstract}
This paper focuses on anaphoric nominal expressions in order to distinguish the specific characteristics presented by expressions of metadiscursive nature in the process of textual references construction and referention progression. Such specific characteristics, related to self-reflexive peculiarity which defines the metadiscourse, differ from the comparasion between metadiscursive nominal anaphora and anaphoric nominal forms carrying informative function such as the definite and indefinite descriptions, nominalizations and associative anaphora.
\end{abstract}

\section{PRELIMINARES}

No contexto do Projeto de Gramática do Português Falado (PGPF), idealizado e coordenado por Ataliba Teixeira de Castilho, foi constituído o Grupo de Organização Textual - Interativa, sob a responsabilidade de Ingedore G. Villaça Koch. As pesquisas desenvolvidas por esse GT tiveram por fundamento uma Proposta Teórica (Koch et al., 1995) sedimentada em princípios da Pragmática, da Análise da Conversação e da Lingüística Textual de orientação interacional. Tal proposta baseia-se em uma concepção de linguagem como forma de ação, postulando que, no âmbito das relações interativas instituídas em um evento comunicativo, há um jogo de atuações recíprocas entre os interlocutores. Esse jogo projeta-se na materialidade lingüística do texto, particularmente no texto falado, que, em virtude de sua especificidade de produção momentânea, põe à mostra o monitoramento local e contínuo de sua formulação. A linguagem é concebida, portanto, como atividade de interação verbal e, conseqüentemente, como manifestação de uma competência comunicativa que se concretiza por meio de textos, em cujo processamento convergem ações lingüísticodiscursivo-interlocutivas.

Pautando-se por essas concepções de linguagem e de texto, o Grupo acima referido empreendeu estudos sobre estratégias e mecanismos de elaboração do texto falado. Dentre esses estudos, destacamos neste artigo os relativos à referenciação, desenvolvidos por Koch e Marcuschi (cf. Marcuschi \& Koch, 1998; Koch e Marcuschi, 2000; Marcuschi, 2000a; Marcuschi, 2000b; Marcuschi, 2001). Utilizamo-nos também do Ensaio de Koch (1999) intitulado "Referenciação: construção discursiva", apresentado por ocasião de seu Concurso para Titular na Área de Análise do Discurso, realizado no IEL/UNICAMP. Esse Ensaio segue a mesma orientação teórica textual- 
interativa estabelecida para a abordagem de textos falados, mas incorpora dados de corpus escrito. À luz dessas pesquisas, pretendemos iniciar uma discussão a respeito da questão do metadiscurso.

\section{REFERENCIAÇÃO}

Ao focalizarem a referenciação, Marcuschi \& Koch (1998) e Koch e Marcuschi (2000) levam em conta a complexa relação entre linguagem, mundo e pensamento, estabelecida no discurso. Eles fixam-se nas noções de que a língua não é espelho da realidade, uma vez que é histórica e socialmente constituída, e de que a discretização do mundo pela linguagem resulta de uma elaboração cognitivo-social, o que equivale a dizer que os itens lexicais não são meras etiquetas estáveis e prontas para rotular a realidade. Ancorados nessas noções, esses autores vêem a referenciação como um processo discursivo criado na dinâmica interacional, de modo que os referentes são considerados como objetos-de-discurso e não como objetos-de-mundo. Conforme salientam, não se trata de negar a existência da realidade extra-mental, mas de não assumir o sentido tradicionalmente atribuído à referência como representação extensionalista de fenômenos empíricos. Em consonância com essa linha de pensamento e com a perspectiva textual-interativa adotada, a referenciação configura-se como um processo negociado no discurso que resulta na construção de referentes. Ela é "considerada como aquilo que designamos, representamos, sugerimos quando usamos um termo ou criamos uma situação discursiva específica" (Koch, 1999, p.5), no intuito de atingirmos determinados objetivos interacionais.

Este breve resumo sobre a concepção de referenciação formulada por Marcuschi \& Koch (1998) e Koch e Marcuschi (2000) leva a repensar e colocar em outras bases o aspecto representativo ou ideacional da linguagem. Isto porque as entidades designadas em um texto não são apriorísticas, como faria pressupor uma concepção de língua que se esgota na noção de código, e sim diretamente relacionadas com as operações efetuadas pelos sujeitos, na elaboração de seu discurso, para representarem tais entidades, tendo em vista seus propósitos interacionais. Assim, os referentes são gerados no interior do discurso: são introduzidos, conduzidos, retomados, identificados no texto, modificando-se à medida que o discurso se desenrola, por meio de estratégias específicas de referenciação. Nesse sentido, falar de função "representativa" ou "informacional" - como o faremos neste artigo - é entendê-las nessa ótica que considera o processamento de referências como atividade discursiva, segundo o projeto de dizer do locutor em um dado ato comunicativo. A fim de sinalizarmos que esta é a referência da palavra "representativa" neste texto, nós a manteremos sempre entre aspas.

É importante salientarmos, como o fazem Marcuschi \& Koch (1998) e Koch e Marcuschi (2000), que a compreensão do processo de referenciação como atividade textual-interativa não implica conceber a ação discursiva como subjetiva, individual, ocorrencial, dado que ela está intimamente vinculada às condições culturais, sócioideológicas e históricas de uma comunidade lingüística. Como afirma Marcuschi (2001, 
p.5) "não devemos ser ingênuos a ponto de ignorar que as representações de um grupo social têm uma estabilidade bastante grande e que nem tudo é construído a cada momento a partir de um zero cognitivo."

\section{PRINCIPAIS ESTRATÉGIAS DE REFERENCIAÇÃO TEXTUAL}

No estudo da progressão referencial, Koch e Marcuschi (2000) e Koch (1999) colocam em foco os processos fóricos do texto, conferindo um sentido amplo à anáfora, como relação entre dois elementos textuais - o que engloba e ultrapassa a definição tradicional de anáfora como estratégia de retomada, geralmente pronominal, de um item lexical colocado anteriormente no texto, com correferencialidade entre os elementos em relação. Além da pronominalização de um item lexical antecedente, os autores apontam outras configurações anafóricas, em que um elemento lingüístico denominado anáfora, que pode ser um Pro ou SN, remete (retomando-o ou não) a um elemento primeiro chamado fonte, expresso por um SN, ou um SV, ou uma oração, ou um segmento textual. Podem ainda ocorrer casos em que a fonte não está lexicalmente explícita, mas é inferível do cotexto ou de conhecimentos conceituais que envolvem esquemas cognitivos.

Com base nessa concepção abrangente de anáfora, são apresentadas duas estratégias principais de referenciação textual: uso de pronomes e uso de expressões nominais $^{l}$. Neste artigo, vamos no restringir a esta segunda estratégia, pela qual se operam categorizações ou recategorizações de referentes-fonte, ou seja, a atividade anafórica promove aspectualizações e avaliações da fonte, ou predicações de outros atributos ao objeto-de-discurso a que remete, modificando-o em algum ponto. Por esse motivo, a propriedade da co-significatividade não se aplica à relação entre anaforizador e anaforizado, embora possa envolver, mas não necessariamente, correferencialidade. $\mathrm{Na}$ recategorização, a correferencialidade se dá quando está em causa o mesmo objeto-de-discurso, que é retomado por repetições, designações alternativas, sinônimos ou até termos não sinonímicos tornados correferenciais no seu uso, já que a significação é sempre contextualizada. Por outro lado, não se registra correfencialidade no processo de recategorização quando, por exemplo, a fonte é inferida do cotexto anterior ou fundamentada cognitivamente, sem que haja, portanto, remissão a referentes pontuais prévios.

\section{E O METADISCURSO?}

Nos itens anteriores, selecionamos e resenhamos, das pesquisas de Koch e Marcuschi sobre referenciação, algumas observações importantes para o encaminhamento de uma discussão sobre metadiscursividade, uma vez que

${ }^{1}$ Koch e Marcuschi (2000) e Koch (1999) denominam expressões nominais as formas lingüísticas constituídas no mínimo por um Nome, quase sempre acompanhado por um Determinante. 
pretendemos verificar se há diferenças específicas entre expressões nominais anafóricas metadiscursivas, relativamente às que não manifestam a auto-referencialidade do discurso, típica do metadiscurso.

A investigação de possíveis particularidades do metadiscurso, fundamentadas nas colocações desses autores sobre referenciação e progressão referencial, foi motivada pelo fato de que, ao tratarem dos processos pelos quais as expressões nominais procedem a categorizações e recategorizações de referentes, focalizam um de ordem metadiscursiva - rotulações metalingüísticas ou metadiscursivas - a par de outros como descrições definidas ou indefinidas, nominalizações e anáforas associativas.

As explicações e exemplificações que os referidos autores fazem de cada um desses processos levaram-nos à constatação de que os objetos-de-discurso referenciados pelas rotulações metalingüísticas ou metadiscursivas são de natureza diversa da dos demais processos. Nestes, as atividades referenciais recaem sobre:

(a) atribuição, a um referente, de propriedades consideradas pelo locutor como relevantes em função de seu projeto comunicativo em dada situação discursiva, no caso das descrições definidas ou indefinidas. Por meio dessas descrições, um objeto-dediscurso sofre modificações na progressão referencial, seja pelo acréscimo de novos aspectos, seja pela desconsideração de atributos anteriormente expressos, seja ainda pela homologação das transformações pelas quais passou no desenrolar do texto (Marcuschi \& Koch, 1998);

(b) condensação de um conjunto de predicações anteriormente postas no discurso, no caso das nominalizações: há a sumarização de informações contidas em um trecho precedente, que são encapsuladas em um substantivo-predicativo e assim transformadas em objeto-de-discurso (Koch e Marcuschi, 2000 e Koch, 1999);

(c) introdução, pela anáfora, de um referente novo sem uma fonte lexicalmente explícita no texto, mas inferível a partir de elementos nele explícitos ou de uma situação cognitiva, de modo que o co(n)texto fornece dados para "saturar" a interpretação referencial, no caso das anáforas associativas. Em outras palavras, informações expressas no texto antes da entrada do referente novo ou conhecimentos conceitualmente baseados em esquemas cognitivos possibilitam a inferência da referência anafórica (Koch e Marcuschi, 2000; Koch,1999; Marcuschi, 2000 a, 2000b).

A partir da caracterização acima desses três processos de referenciação, depreendemos que eles têm em comum o fato de que promovem a progressão referencial do texto atuando diretamente na organização das informações que são acionadas pelos interlocutores na interação verbal. Servem, portanto, de base para o desenvolvimento dos tópicos discursivos abordados durante um ato comunicativo. As remissões anafóricas das formas nominais, em todos esses processos, fundam-se, assim, na função "representativa" dos enunciados tópicos. 
Já no processo de rotulações metalingüísticas ou metadiscursivas, os objetos-dediscurso não dizem respeito às informações tópicas de natureza "representativa", porque consistem em²:

(a) atos ilocucionários designados por: ordem, promessa, conselho, advertência, crítica, proposta, alegação, afirmação, etc.:

(1) O presidente Carlos Menen visitou o Brasil no auge da crise, mas também nos dias em que, em Washington, o Congresso determinava a sorte do fast track, legislação essencial para que o presidente Bill Clinton pudesse acelerar o processo de criação da Alca (...): “A consolidação e o aprofundamento do Mercosul constituem a prioridade número um da política externa da República Argentina”. A afirmação foi feita no Senado, em Brasília (...) (Editorial, O Estado de São Paulo, 14/11/97)

(b) atividades linguageiras, designadas por: descrição, explicação, relato, esclarecimento, comparação, comentário, história, controvérsia, debate, exemplo, ilustração, definição, etc. Ver os comentários no exemplo (2) abaixo.

(c) processos mentais, designados por: análise, suposição, atitude, opinião, conceito, convicção, avaliação, constatação, etc. Ver a avaliação em (2):

(2) Os governos dos países da América Latina podem colocar em risco o crescimento da região se elevarem muito os juros e cortarem despesas de forma drástica para defender o valor das moedas.

A avaliação é de Charles Adams, diretor assistente de pesquisa do FMI (...) Os comentários de Adams refletem o receio de que fórmulas tradicionalmente defendidas possam levar à recessão (...)

(d) atributos do âmbito da língua ou do texto, designados metalingüisticamente por: frase, pergunta, sentença, palavra, termo, parágrafo, etc.:

(3) O premiê (Tony Blair) aproveitou para rejeitar "a imposição de novos escudos para controlar o movimento internacional de capitais ou o recuo no livre comércio".

A frase é mais uma evidência de quanto se dissemina, entre os dirigentes dos partidos ricos, o temor de que os mercados emergentes recorram a medidas que fujam do receituário liberal.

(Folha de São Paulo, 22/09/98)

Diferentemente das referências de fundo "representativo" instituídas pelos três processos apontados anteriormente, os referentes rotulados metalingüística ou metadiscursivamente em todos os exemplos acima são claramente entidades do discurso, no sentido de que focalizam a atividade enunciativa, a "mise-en-scène" do discurso, conforme explicamos a seguir.

${ }^{2} \mathrm{O}$ detalhamento das rotulações metalingüísticas ou metadiscursivas, bem como os exemplos abaixo transcritos estão em Koch (1999). 
Observamos que, em (1), a expressão nominal a afirmação remete anaforicamente à citação da fala de Menen, sem fazer referência ao seu conteúdo proposicional, porque a toma enquanto ato de fala, categorizando-o pela sua força ilocucionária de asserção. Logo, a expressão anafórica desloca o foco do texto para o plano da enunciação, visto que denomina a ação verbal praticada pelo enunciador do discurso relatado, e simultaneamente a predica pelo seu teor asseverativo.

Em (2), os SNs a avaliação e os comentários fazem remissão às proposições tópicas imediatamente precedentes, para atribuir, ao conjunto delas, propriedades de ordem enunciativa, na medida em que eles categorizam seus respectivos contextosfonte como atos de enunciação: avaliação e comentário são designações de atividades linguageiras, associadas a processos mentais, que o escritor do texto imputa ao responsável pelas informações que reproduz. Conseqüentemente, as relações entre essas expressões nominais anafóricas e suas fontes não se operam no mesmo nível de progressão do tópico discursivo, pois enquanto a fonte comporta uma função de processamento de informações tópicas, a anáfora explicita a modalidade de ato enunciativo praticado nesse processamento.

Em (3), a forma nominal $\boldsymbol{a}$ frase, à semelhança de (1), remete anaforicamente a uma citação de fala, agora de Tony Blair, sem que haja uma relação entre anaforizador e a citação-fonte calcada no seu conteúdo proposicional. Isto se deve ao fato de que a anáfora rotula a fonte com um termo da metalíngua - o que provoca um desdobramento de planos discursivos contextualizadores da citação. Ao ser posta no discurso, a citação se configura como uma informação, mas ao ser designada como frase, ela se transforma em suporte de uma predicação discursiva, já que passa a ser referenciada como uma unidade de construção do texto. Dado que se repete, neste caso, o mesmo mecanismo de referenciação discursiva verificado nas rotulações metadiscursivas vistas em (1) e (2), consideramos as situações de metalinguagem dentro do quadro geral de metadiscurso.

O ponto de conjunção entre os fatos que acabamos de comentar é o de que, em todas as ocorrências de rotulação metalingüística ou metadiscursiva, há esse jogo multiplano em que referentes textuais constitutivos do elemento-fonte anaforizado desempenham uma função informacional no texto e passam, no anaforizador, a se constituir como objetos de menção e qualificação no contexto da atividade enunciativa. O discurso dobra-se sobre si mesmo, em um movimento auto-reflexivo típico da metadiscursividade, figurando como discurso e objeto-de-discurso.

\section{O DISCURSO COMO OBJETO-DE-DISCURSO}

$\mathrm{Na}$ atividade de referenciação textual, efetuada por meio de formas nominais anafóricas, a diferença que há entre os vários processos indicados por Koch e Marcuschi (2000) e Koch (1999) reside, como visto no item anterior, nessa propriedade de auto-reflexividade do discurso, que particulariza as rotulações metalingüísticas ou metadiscursivas e não se verifica nos demais processos. 
Em decorrência dessa diferença, passamos a verificar se há peculiaridades do metadiscurso quanto à categorização de referentes que as expressões nominais anafóricas processam na progressão referencial.

Inicialmente, cumpre lembrar que o elemento já posto no discurso, ao qual as expressões nominais sob estudo fazem remissão, exceto as anáforas associativas que não têm antecedente explícito, pode ser um item lexical ou um segmento textual. Os exemplos de (1) a (3), atrás, demonstram a categoria anafórica de remeter a uma porção textual precedente, através de um procedimento de metadiscurso. O (4), abaixo, que selecionamos de um levantamento que fizemos em material do NURC, ilustra essa mesma categoria, sendo que o foco da anáfora metadiscursiva é um item lexical:

(4) Inf. ... outra coisa ... é eu falar em es-TI-lo ... naturalista ... e naturalista aqui realista ... isto é:: não é a a a ... realidade idealizada MAS a realidade de Fato ... que vai ser retratada $(\mathrm{EF} \mathrm{SP}-405)^{3}$

Em (4), embora não haja no segmento em negrito uma rotulação metadiscursiva, sob a forma de um nome metalingüístico como "a palavra" naturalista, ele é perfeitamente compreensível no cotexto, visto que, se na primeira ocorrência de naturalista esse item lexical é "usado" em um enunciado tópico de base informacional, na segunda ocorrência ele é "mencionado" na sua qualidade de palavra, dado que está em causa a explicitação de sua significação enunciativa ${ }^{4}$. Sua referência é, desse modo, construída especificamente nesse discurso (veja-se o uso do aqui), neste ato interacional: realista é o que o locutor representa para o seu interlocutor quando usa o termo naturalista. A segunda entrada desse item lexical no texto faz remissão à primeira, caracterizando um processo anafórico, no qual a repetição é uma expressão nominal com função claramente metadiscursiva: o discurso referencia as referências nele acionadas.

A passagem de "uso" a "menção" do termo naturalista tem por correlata a passagem de uma situação informacional para outra em que o foco é o próprio discurso, mais propriamente a atividade enunciativa, já que especificações das significações contextualizadas reportam-se à elaboração dinâmica de referências em uma interação verbal. Conseqüentemente, apesar da repetição lexical contígua, não se registra aí uma retomada do referente imediatamente anterior como atividade de continuidade de um núcleo referencial, como acontece quando há retomadas por descrições definidas e nominalizações ${ }^{5}$, em que a(s) forma(s) remissiva(s), por ser(em) da mesma ordem informacional que a fonte do processo anafórico, acarretam progressão textual na

${ }^{3}$ O EF SP - 405 está publicado em CASTILHO, A. T. e PRETI, D. (orgs.) (1986). O segmento (4), aqui transcrito, está na página 55, linhas $306-310$.

${ }^{4}$ Marcuschi (2001:6), ao explicar que os referentes são objetos-de-discurso e não objetos-do-mundo, admite que "a significação lingüística (supostamente lexicalizada) não se confunde com a significação enunciativa (emergente no processo de enunciação)".

${ }^{5}$ Trataremos posteriormente das anáforas associativas, devido à peculiaridade de elas não terem fonte explícita. 
mesma direção referencial. Temos aqui, portanto, uma primeira especificidade das formas nominais anafóricas metadiscursivas: nunca há retomada referencial.

A essa impossibilidade de retomada de referentes, associa-se um segundo fato particularizador das expressões metadiscursivas: nunca há correferencialidade entre fonte e anáfora. Enquanto a outros processos de referenciação anafórica pode ser aplicável a propriedade da correferenciação ${ }^{6}$ entre anaforizador e anaforizado, porque, como acabamos de dizer, ambos têm a mesma natureza referencial, aos metadiscursivos ela é bloqueada. Esse bloqueio ocorre por causa da diferença de modalidades de referenciação entre fonte e anáfora: a fonte comporta função informacional, no sentido de representação discursiva de uma exterioridade textual e a anáfora faz uma autorepresentação do processamento do discurso. Por isso, à reiteração do item lexical naturalista, no segmento (4), não corresponde um processo correferencial: a identidade de designação constante da forma remissiva e de seu antecedente não significa que se trata do mesmo objeto-de-discurso, pois a segunda ocorrência do termo não reativa o mesmo referente da primeira, e sim menciona o termo, representando-o no seu estatuto de palavra. Este é um exemplo claro de que os referentes textuais se constituem no discurso.

Em virtude das especificidades que a não-retomada referencial assume nas expressões nominais anafóricas metadiscursivas, a característica de não cosignificatividade de todas as remissões referencias recategorizadoras fundamenta-se, no caso do metadiscurso, em parâmetros diferentes dos que vigoram para anáforas não metadiscursivas concretizadas por descrições definidas ou indefinidas ou por nominalizações. Nas descrições definidas ou indefinidas, fonte e anáfora não são cosignificativas pelo fato de que, na progressão referencial, o anaforizador recategoriza o referente-fonte, modificando-o com a introdução de novos atributos, confirmando alterações de predicações havidas anteriormente,ou até não levando em conta mudanças anteriores. Está em causa, portanto, a construção referencial de um objeto-de-discurso assentada na função "representativa", de como os referentes textuais são dinamicamente construídos pela atividade enunciativa, servindo de base para a elaboração dos tópicos discursivos abordados em um intercâmbio verbal. $\mathrm{O}$ mesmo ocorre com as nominalizações, que transformam um conjunto de informações previamente postas no texto em um objeto-de-discurso condensador dessas informações. Por outro lado, as formas nominais que desempenham o papel de anaforizadoras metadiscursivas não são co-significativas em relação às suas fontes porque elas têm a peculiaridade de instituir o discurso como objeto-de-discurso, ao passo que suas fontes consistem em objetos-dediscurso referencialmente fundados na informatividade textual. Conseqüente e obviamente, essa propriedade auto-reflexiva específica do metadiscurso impede a cosignificatividade com objetos-de-discurso que comportam uma referência de ordem informacional. Retomando o segmento (4), constatamos que a ausência de co-

${ }^{6}$ Conforme o que dissemos no final do item 3, a correferencialidade não é condição necessária de relações anafóricas, mas pode ser instituída no texto, se houver remissão ao mesmo objeto-de-discurso. Neste ponto do artigo, referimo-nos tão somente ao fato de a propriedade da correferencialidade poder ser observada em processos anafóricos outros que não os metadiscursivos. 
significatividade entre as duas ocorrências de naturalista baseia-se precisamente nessa diferença de foco referencial e não em mudanças de atributos predicados a um objetode-discurso, no mesmo plano "representativo". A predicação que a anáfora estabelece para naturalista não diz respeito a modificações referencias atributivas de um objetode-discurso e sim ao processamento do discurso, para assinalar a significação enunciativa conferida ao uso dessa palavra no enunciado tópico anterior.

Complementando essas observações sobre particularidades de anáforas nominais metadiscursivas, passamos a focalizar as expressões nominais que funcionam no texto como anáforas associativas - às quais ainda não nos referimos -, a fim de contrapormos essas duas modalidades do processo anafórico. Marcuschi \& Koch (1998), ao tratarem de transformações operadas ou marcadas pela anáfora, especificamente de reategorização com modificação da extensão do objeto ou de seu estatuto lógico, arrolam, dentre outros casos, "a passagem a um nível metalingüístico, uma tranformação que se assemelha a uma anáfora associativa. Trata-se de uma passagem que vai do "uso" de uma expressão para a sua "menção", daí seu caráter metalingüístico." (p. 186, grifos nossos). O segmento (4) cabe perfeitamente como elucidação desse fato. Cumpre repetir aqui, num parêntese, uma observação anterior de que, desde que haja "menção" de um elemento do texto, constatamos auto-reflexividade discursiva e estamos, portanto, diante de um procedimento de metadiscurso. Por isso englobamos o que Marcuschi \& Koch (1998) consideram como metalingüístico dentro da metadiscursividade. Voltando à citação acima, importa-nos destacar nela a indicação dos autores de que há semelhanças entre procedimentos metalingüísticos (diríamos metadiscursivos) e anáforas associativas. Procurando investigar quais poderiam ser essas semelhanças, concluímos que efetivamente há pontos de contato entre os dois processos sob comparação, que se sustentam, no entanto, em características que os diferenciam:

(a) ambos introduzem referente novo. A anáfora associativa porque não tem um referente-fonte lexicalmente atualizado no texto. A anáfora metadiscursiva porque em geral faz remissão a um trecho precedente sem pontualizar um referente nele expresso (exemplos 1 a 3 ) ou, mesmo que tenha uma fonte previamente explicitada (exemplo 4), transforma-a em outro objeto-de-discurso, muito diferente do da fonte, pois instaura como referência o discurso, na passagem de "uso" (na fonte) a "menção" (no anafórico), conforme o demonstramos na análise do segmento (4);

(b) por causa da particularidade exposta em (a), ambos os processos de referenciação aqui focalizados não reativam elementos prévios, não havendo, portanto, retomada de referentes. Entretanto, a anáfora associativa subentende continuidade de um núcleo referencial, pois há alguma relação semântica ou conceitual entre a forma anafórica e o co(n)texto que fundamenta sua interpretação. Daí serem elas associativas. Já na anáfora metalingüística, inexiste uma relação, nem mesmo associativa, indireta, entre a expressão anafórica e o(s) elemento(s) a que remete, em consequiência do fato de anaforizador e anaforizado terem funções discursivas 
diversificadas: "representativa" nos enunciados tópicos da fonte e auto-reflexiva o discurso como objeto-de-discurso - na anáfora. Tal diferença faz despontar outra: a anáfora associativa tem um ponto de ancoragem interpretativa nas relações semânticas e conceituais não lexicalizadas mas situadas no texto; a metadiscursiva apóia-se na glosa sobre o discurso que ela cria no texto, sem uma âncora que dê suporte à sua interpretação.

(c) pelas características referidas em (a) e (b), nem a anáfora associativa nem a metadiscursiva admitem correferencialidade. Para atestar que a correferencialidade é incompatível com esses dois processos, importa ressaltar, das propriedades definidoras de um e outro, mencionadas nos itens anteriores, que a referência da anáfora associativa é uma inferência calcada em relações semântico-textuais ou cognitivo-contextuais e a referência da anáfora metadiscursiva consiste em uma auto-representação do dizer pelo enunciador do texto. Assim, nenhuma das duas pode admitir relação correferencial com elementos textuais de outra natureza referencial, como o dos objetos-de-discurso "representativos".

Em síntese, a despeito dos pontos de intersecção entre as anáforas associativas e as metadiscursivas, a explicitação de suas diferenciações acaba por enfatizar as propriedades das expressões nominais anafóricas metadiscursivas. Somadas às demais diferenças dessas expressões, vistas anteriormente, quando cotejamos o processo de rotulações metalingüísticas ou metadiscursivas com os de descrições definidas ou indefinidas e nominalizações, elas encaminham para e sustentam a afirmação de que, com efeito, as formas nominais anafóricas que desempenham função metadiscursiva têm peculiaridades que as distinguem fundamentalmente das de ordem "representativa".

\section{CONSIDERAÇÕES FINAIS}

Tomando como fundamento as pesquisas de Koch e Marcuschi sobre referenciação e progressão referencial, focalizamos neste artigo as expressões nominais anafóricas, com o propósito de verificar se haveria diferenças entre os tipos dessas expressões, que pudessem evidenciar particularidades do metadiscurso. Confrontamos as formas metadiscursivas com as demais, tendo chegado à conclusão de que as expressões nominais anafóricas em que se manifesta o metadiscurso apresentam especificidades diretamente associadas à propriedade básica definidora do metadiscurso, que é a da auto-reflexividade discursiva.

Essa conclusão nos leva a aventar a possibilidade de entender as formas nominais anafóricas "representativas" como subtipos de uma classe que promove a continuidade referencial em termos informacionais, contraposta a uma outra classe, a metadiscursiva, que opera uma espécie de desdobramento do discurso: o discurso como objeto-dediscurso, estabelecendo-se como referência de si próprio. Esse desdobramento seria o 
traço distintivo entre as duas classes, uma vez que cria uma outra modalidade de referenciação, diversa da "representativa".

Procuramos, neste artigo, indicar algumas pistas para uma discussão mais ampla sobre metadiscursividade que, na linha dos estudos de Koch e Marcuschi a respeito de referenciação, deve dar conta da questão de como se processa, na produção discursiva, a referenciação auto-referencial do discurso.

\section{$\overline{\text { REFERÊNCIAS BIBLIOGRÁFICAS }}$}

CASTILHO, A.T. \& PRETI, D. (orgs.). (1986). A Linguagem Falada Culta na Cidade de São Paulo. São Paulo: T. A. Queiroz, vol. I - Elocuções Formais.

KOCH, I.G.V. (1999). Referenciação: construção discursiva. Ensaio apresentado por ocasião do Concurso para Titular na Área de Análise do Discurso no IEL, UNICAMP. (mimeo).

KOCH, I.G.V. et al. (1995). Proposta teórica para a análise textual-interativa de textos falados. (mimeo).

KOCH, I.G.V. \& MARCUSCHI, L.A. (2000). Estratégias de referenciação no texto falado. Texto apresentado para publicação na obra (em organização) Gramática do Português Culto Falado no Brasil. vol 1 - Construção do Texto Falado. (mimeo).

MARCUSCHI, L.A. \& KOCH, I.G.V. (1998). Processo de referenciação na produção discursiva. Revista D.E.L.T.A.vol. 14, Número Especial.

MARCUSCHI, L.A. (2000a). Anáfora sem antecedente explícito. In: PRETI, D. (org.). Fala e Escrita em Questão. São Paulo: Humanitas. (Projetos Paralelos - NURC/SP, Núcleo USP, vol. 4)

. (2000b). Anáfora indireta: o barco textual e suas âncoras. Texto apresentado na IV Jornada do CelSul, Universidade Federal do Paraná, Curitiba.(mimeo).

. (2001). Atividades de referenciação no processo de produção textual e o ensino de língua. Texto apresentado no I Encontro Nacional do GELCO, Campo Grande. (mimeo). 